\title{
O FRACASSO DE LEITURA EM FAUSTO DE FERNANDO PESSOA
}

\author{
Tatiana de Freitas Massuno ${ }^{1}$
}

RESUMO: O caráter inacabado de Fausto de Fernando Pessoa fez com que estudiosos pensassem que tal projeto seria impossível. O presente estudo também se baseia na impossibilidade. Entretanto, a impossibilidade aqui será pensada de duas formas: enquanto um problema formal e, no que tange ao conteúdo, enquanto impossibilidade de leitura. Através destas duas apreensões, busca-se uma investigação da forma por meio da qual o drama poético pode ser entendido como sendo uma alegoria, na acepção benjaminiana do termo.

PALAVRAS-CHAVE: impossibilidade; alegoria; leitura.

\section{READING FAILURE IN FAUSTO BY FERNANDO PESSOA}

\begin{abstract}
Fausto's unfinishedness made scholars think such a project as impossible. Therefore, this present study seeks an understanding of the Faustian problem in Fernando Pessoa from the perspective of its inherent impossibility. Impossibility here is twofold: as a formal problem and, as far as content is concerned, as an impossibility of reading. From these two viewpoints, we intend to investigate how Primeiro Fausto or Tragédia Subjectiva can be read as allegories, in Benjamin's term.
\end{abstract}

KEYWORDS: impossibility; allegory; reading.

\footnotetext{
${ }^{1}$ Doutoranda em Literatura Comparada (UERJ).
} 
O presente trabalho busca entender de que forma o Fausto de Fernando Pessoa pode ser apreendido como uma alegoria, na acepção benjaminiana do termo. O que se sustentará é que o drama poético pessoano se apresenta como uma alegoria tanto no que tange ao seu conteúdo quanto no que diz respeito a sua forma. Formalmente, a obra impõe um problema aos estudiosos de Fernando Pessoa - a sua incompletude. Embora tenha Fausto ocupado boa parte da vida produtiva de Fernando Pessoa, os primeiros poemas datam de 1908 enquanto os últimos, de 1933; restam-nos, apenas, seus projetos e as organizações dos poemas, seja por parte de Duílio Columbini, seja por Teresa S. Cunha. Dessa forma, tendese a conceber o drama em questão como sendo uma obra "inacabada" por duas razões: a primeira diz respeito à própria organização dos poemas, não tendo sido efetuada por Pessoa; e a segunda refere-se ao fato de que, inicialmente, o poeta vislumbrara que o drama Fausto deteria três partes e resta-nos, no entanto, apenas uma. Outro agravante que parece justificar o chamado caráter "inacabado" se revela quando da leitura dos versos. Algumas palavras parecem não ter sido resolvidas por Pessoa, são simplesmente inexistentes; o que confere ao drama a sensação de incompletude.

O que se pretende, pois, é pensar a impossibilidade inerente a Fausto e tentar perceber de que forma interpretações distintas da impossibilidade presente no drama poético podem ser entendidas como apreensões de seu caráter alegórico. Dessa forma, a impossibilidade será pensada sob duas perspectivas: enquanto impossibilidade de o poema se constituir em uma totalidade (forma) e enquanto impossibilidade de leitura (conteúdo).

Creuzer, ao tentar manter a distância entre símbolo e alegoria, aponta que no símbolo, diferentemente da alegoria, tem-se a encarnação de uma ideia. Enquanto, em sua concepção, a alegoria significaria algo, o símbolo, por outro lado, não significaria, mas seria ele próprio a ideia. Através da imagem veríamos a ideia que teria se materializado no mundo físico. O que postula o símbolo, portanto, é a imediatez, identidade, e não meramente uma relação entre aparência e essência (BENJAMIN, 2003, p. 160). Walter Benjamin observa que desde o início do romantismo predominava uma ideia de símbolo que não possuía mais relação com sua origem: o símbolo teológico. O paradoxo do símbolo teológico residiria na unidade material e transcendental do objeto (BENJAMIN, 2003, p. 160). Benjamin não está sozinho ao perceber que o dito símbolo moderno perdera sua origem transcendental ou metafísica, Gadamer também apreende as modificações nas conceituações de símbolo. O símbolo possui um pano de fundo metafísico uma vez que, a partir do sensorial, pode-se ser levado ao divino. Desta forma, postula a coincidência entre 
duas esferas: o visível e o invisível, o sensorial e o metafísico, o humano e o divino (GADAMER, 1999, p. 136). Paul de Man observa que a estrutura do símbolo é a sinédoque já que o símbolo é parte da totalidade que representa, não havendo, por conseguinte, qualquer tipo de disjunção: "since the material perception and the symbolical imagination are continuous, as the part is continuous with the whole" (MAN, 1988, p. 191).

Em Fausto de Fernando Pessoa há também a relação entre o humano e divino, o visível e o invisível encontrado nas concepções de símbolo:

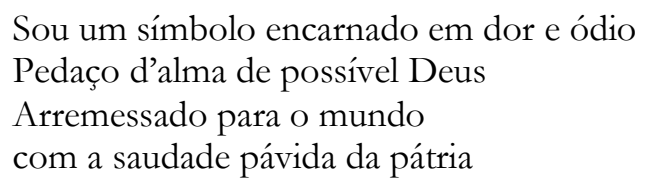

Apesar de ser um pedaço do divino, uma possível parte da totalidade, Fausto vive um “desterro" (PESSOA, 1991, p. 112). Afinal, é um possível Deus, provavelmente um Deus de outro Deus, quiçá haveria qualquer outro Deus, ou Deuses de Deuses. Fausto, por demais consciente, não consegue sequer amaldiçoar esse possível Deus por seu desterro, embora mencione que possa ser pedaço do divino. Não consegue amaldiçoá-lo por suspeitar ser Deus apenas mais uma ilusão. Sendo pedaço, parte de uma divindade ou não, o que se apresenta em Fausto não é uma relação de identidade, uma relação contínua entre parte e todo, mas uma disjunção. Fausto é um desterrado, arremessado ao mundo, não sendo mais capaz de comunicar ou compreender a esfera invisível ou metafísica: "Expulso embora da divina essência" (PESSOA, 1991, p. 19).

A identidade ou imediatez do símbolo estaria, na visão fáustica, interrompida:

Ah, tudo é símbolo e analogia! O vento que passa, a noite que esfria

São outra coisa que noite e vento -

Sombras de vida e de pensamento

Tudo que vemos é outra coisa.

A maré vasta, a maré ansiosa,

É o eco de outra maré que está

Onde é real o mundo que há

Tudo que temos é o esquecimento

A noite fria o passar do vento

São sombras de mãos cujos gestos são

A ilusão mãe desta ilusão

(PESSOA, 1991, p. 5) 
O mundo físico que se põe ante aos olhos de Fausto não coincide com a esfera invisível. Para Fausto, seja a maré, seja a noite ou o vento, não são parte de uma totalidade, porém "outra coisa". Este apontar para outra coisa se encontra no cerne do que Benjamin concebe como a alegoria:

that all of the things that are used to signify derive, from the very fact of their pointing to something else, a power which makes them appear no longer commensurable with profane things, which raises them onto a higher plane, and which can, indeed, sanctify them (BENJAMIN, 2003, p. 175).

Com sua queda e tendo, subsequentemente, sua transcendência interditada, o que Fausto obtém é justamente o esquecimento. Esquecimento da pátria de onde fora arremessado; esquecimento, portanto, do mundo real que não corresponderia a este que há. O mundo que há é o mundo de sombras que não ilumina ou esclarece a presença do mundo outro ou mundo invisível onde se encontra o real. O que Fausto vê, portanto, não carrega consigo a iluminação momentânea de uma revelação, muito pelo contrário, vê apenas sombras - gestos de uma ilusão. Os símbolos que vê são símbolos cifrados que não trazem em si a relação de identidade com o real. A queda interrompeu qualquer tipo de possibilidade de identidade, imediatez ou coincidência entre visível e invisível. Apontam para outra coisa. Entretanto, Fausto, que percebe o mistério imanente em tudo, permanece no campo da imanência, sua transcendência encontra-se interditada, não há como voltar à pátria.

Apontar, dessa forma, para outra coisa implicaria perceber que o que se apresenta não se mostra como encarnação de uma ideia, mas que o sentido encontra-se fora das coisas. Fausto de Fernando Pessoa conta a história de sucessivas tentativas de busca de sentido. Entretanto, como não se encontra no campo de identidade entre as esferas sensoriais e divinas, entre o visível e o invisível, as tentativas revelam-se sempre falhas. Portanto, Fausto, como tentativas sucessivas de busca de um sentido último que sempre escapa, contaria a história do que entende Paul de Man como fracasso de leitura que seria engendrada em narrativas alegóricas:

As narrativas alegóricas contam a história do fracasso da leitura, enquanto as narrativas tropológicas, tais como Segundo Discurso, contam o fracasso da denominação. A diferença é apenas uma diferença de grau, e a alegoria não apaga a figura. As alegorias são sempre alegorias de metáforas e, como tal, sempre alegorias de uma impossibilidade de leitura. (MAN, 1996, p. 233) 
Em seu estudo sobre o romance Julie ou A Nova Heloísa, Paul de Man afirma que o romance em questão, como uma alegoria, tematiza a questão da leitura ou, o fracasso ou impossibilidade desta. Partindo-se, assim, do romance em questão, o autor conclui que, de fato, narrativas alegóricas contam a história deste fracasso haja vista que as leituras são leituras que sempre se mostram em erro. Em Fausto de Fernando Pessoa a leitura está também sendo tematizada:

\title{
O Mistério \\ Deste mundo \\ Teu profundo \\ Olhar leu;
}

$$
\text { (PESSOA, 1991, p. 10) }
$$

A leitura, entretanto, longe de ser uma prática inocente, se revela como "o ponto de partida de todo o mal" (MAN, 1996, p. 221): "Li vaga - inerte - e sonhadoramente li/ Compreendendo mais do que havia/ Em frase (...)" (PESSOA, 1991, p. 8). Compreender mais do que havia em frase instaura em Fausto a presença do mistério que não o abandonará, mas que persiste em sua alma. Compreender, portanto, mais do que havia em frase refere-se justamente a este apontar para outra coisa. A leitura é sempre uma leitura para fora, compreende-se além do que está escrito; leitura, portanto, que por não postular uma identidade entre o sentido e a escrita, visto que sentido e escrita encontram-se em esferas não idênticas, resvala em erro. A leitura fracassa:

\author{
O mistério de tudo \\ Aproxima-se tanto do meu ser, \\ Chega aos olhos meus d'alma tão perto \\ Que me dissolvo em trevas e imerso \\ Em trevas me apavoro escuramente
}

(PESSOA, 1991, p. 11)

O ambiente fáustico é, portanto, um ambiente que de forma alguma ilumina, mas que enegrece. Aproximar-se do mistério seria ter perante si apenas mais escuridão, o que provocaria, novamente, mais leituras errôneas. O próprio projeto de Pessoa para seu Fausto aponta que: "O conjunto do drama representa a luta entre a Inteligência e a Vida em que a Inteligência é sempre vencida” (FAUSTO, 1991, p. 190). O cerne temático de Fausto seria proveniente das várias tentativas da Inteligência de "compreender a Vida", "dirigir a Vida", "se adaptar à Vida" (FAUSTO, 1991, p. 190), "de dissolver a Vida", resultando na "falência final da Inteligência" (FAUSTO, 1991, p. 191). Dessa forma, percebe-se que o plano 
pessoano para a constituição dos atos e entreatos pertencentes ao drama revela que todas as tentativas por parte da Inteligência são tentativas mal fadadas, que levam à falência final da Inteligência: "O pensamento é enterrado vivo / No mundo e ali sufoca" (PESSOA, 1991, p. 21). Portanto, o projeto de Pessoa alude ao fato de ser o drama encerrado por várias instâncias de fracasso da Inteligência. Por conseguinte, o drama conta a história do fracasso da Inteligência ante a Vida, fracasso de leitura da Vida: alegoria.

Fausto de Fernando Pessoa, como uma alegoria, conta a história da progressão de diferentes momentos que se reverberam, consequentemente, em diferentes momentos de leitura da Vida. Momentos estes que pela falta de imediatez se mostram como leituras sempre errôneas. Fausto, entretanto, não apenas em seu conteúdo se instala como uma alegoria, mas também, formalmente, pode ser considerado uma alegoria. Fato que problematiza, assim, sua própria leitura.

O conceito de alegoria benjaminiano é tratado por Peter Bürger em Teoria da Vanguarda como um conceito bastante complexo que pode ser lido como teoria para a obra de arte vanguardista. Embora tenha Benjamin desenvolvido o conceito de alegoria a partir do drama barroco, Bürger afirma que a alegoria encontra, na obra de arte de vanguarda, seu objeto adequado. A justificativa para tal residiria no fato de Walter Benjamin ter desenvolvido o conceito de alegoria com os olhos voltados para as obras de vanguarda: "a experiência de Benjamin no trato com as obras de vanguarda é que possibilita tanto o desenvolvimento da categoria como sua aplicação à literatura barroca e não o inverso" (BÜRGER, 2008, p. 140).

Bürger analisa de que forma o conceito de alegoria benjaminiano poderia ser apreendido como uma teoria da obra de arte vanguardista a partir de dois tipos de interpretação: a estética da produção e a estética da recepção. Em termos de estética de produção, o artista vanguardista trataria seu material não como algo vivo, mas arrancaria-o de seu contexto original. Enquanto na obra de arte orgânica (clássica) o material seria tratado como totalidade, tendo sentido por si só; na obra de arte não-orgânica (vanguardista), por outro lado, o sentido é um sentido atribuído pelo artista. Vê-se, portanto a correlação com o conceito de alegoria desenvolvido por Benjamin:

If the object becomes allegorical under the gaze of melancholy, if melancholy causes life to flow out of it and it remains behind dead, but eternally secure, then it is exposed to the allegorist, it is unconditionally in his power. That is to say it is quite incapable of emanating any meaning or significance of its own; such significance as it has, it acquires from the allegorist. (BENJAMIN, 2003, p. 184). 
Na obra de arte não-orgânica, portanto, o material é tratado como um algo morto. A partir do momento em que foi extraído de seu contexto original, o sentido que emana é um sentido não mais próprio, inerente ao material; porém, concedido, atribuído. A obra de arte orgânica é criada como uma totalidade, a obra de arte vanguardista, entretanto, configura-se não mais como totalidade, mas como uma junção de fragmentos cujos sentidos lhe foram atribuídos.

No que tange à estética da recepção, as diferenças entre obras de arte orgânicas e não-orgânicas são também bastante significativas. A obra de arte orgânica é apreendida como uma obra da natureza. A obra vanguardista, no entanto, é reconhecida como um artefato, construída através de fragmentos, rompendo, assim, com a aparência de totalidade. Se a obra de arte clássica é apreendida como uma totalidade, as partes adquirem significado quando relacionadas ao todo da obra; na obra vanguardista, entretanto: "os movimentos individuais possuem um grau mais elevado de autonomia e podem, por isso ser lidos e interpretados também individualmente ou em grupos, sem que o todo da obra tenha de ser apreendido" (BÜRGER, 2008, p. 147).

O que se observa na obra de arte vanguardista, que teria como teoria o conceito de alegoria benjaminiano, refere-se à autonomia das partes constitutivas quando comparadas ao todo da obra de arte. Como não há a intenção de uma totalidade já que as partes não estão relacionadas a uma questão de necessidade, as partes se emancipam. Não havendo, portanto, a totalidade da obra, sendo constada, pois, seu caráter fragmentário, perguntar que sentido a obra teria se tornaria incongruente com a própria constituição das obras de arte não-orgânicas.

Esse pequeno desvio pelo pensamento de Peter Bürger não se insere aqui para que se conclua que, de fato, Fausto de Fernando Pessoa poderia ser concebido como uma obra de vanguarda. A obra de vanguarda é um tipo de obra que se rebela contra a instituição arte, realizando essa destruição - da instituição arte - na própria arte (BÜRGER, 2008, p. 147). A arte não-orgânica como não possuindo as partes relacionadas ao todo da obra, é um tipo de arte em que há “a renúncia à interpretação de sentido” (BÜRGER, 2008, p. 160) já que o sentido não pode mais ser inferido às custas da leitura das partes. A relação das partes com o todo não é mais uma relação de necessidade. Embora se possa afirmar que há a autonomia dos poemas constituintes de Fausto, eles podem ser lidos como poemas autônomos, não seguindo, dessa forma, uma organização sequencial; há, contudo, uma 
ideia sendo desenvolvida: a falência da Inteligência perante a Vida. Os poemas, mesmo que autônomos entre si, reiteram a temática do drama poético. A própria posição de Pessoa com relação às obras de vanguarda fica evidente em sua carta a Marinetti. Pessoa afirma estar de acordo com o Futurismo em um sentido: condena o simples racionalismo. Entretanto, declara que se deve caminhar além do simples racionalismo, deve-se "atravessálo". A “simples impressão imediata das coisas", para Fernando Pessoa, não é o bastante uma vez que: "Devemos conhecer, compreender, sentir de forma absolutamente pura a razão íntima (interna) das coisas e de como são engendradas (produzidas)" (PESSOA, 1998, p. 305). Termina, então, sua carta afirmando que se os futuristas condenam o próprio pensamento, esta não é a sua posição. Não condena o pensamento. Busca, entretanto, o pensamento puro. Portanto, se há rebelião na obra de Pessoa, a rebelião não é à instituição arte, ou ao pensamento como concebeu o poeta acerca do futurismo, a rebelião se instaura contra o simples racionalismo.

Fausto de Pessoa se instala formalmente como uma alegoria, no entanto, esse simples fato não deve relacioná-lo a obras de vanguarda. Josiane Maria de Souza, em O Fausto de Fernando Pessoa: a totalidade inatingivel, ao afirmar que a única existência possível para Fausto seria a sua existência enquanto fragmentos, de certa forma, partilha do argumento de que o drama se apresenta formalmente como uma alegoria. Garantir a existência de Fausto em seu caráter de fragmentos é possibilitar que os fragmentos possuam certa autonomia, quando relacionados ao todo da obra. Os poemas constituintes de Fausto seriam, desse modo, autônomos, próximos ao que Peter Bürger concebeu como obra não-orgânica, que teria no conceito de alegoria sua teoria. Entretanto, se os poemas de Fausto podem ser lidos como poemas autônomos e a organização dos mesmos pode ser questionada e revista, alterada, isto se deve, primordialmente, à atenção à natureza do conteúdo da obra. $\mathrm{O}$ drama representaria a luta entre Inteligência e Vida. Portanto, o drama tem como material a Inteligência. Entretanto, Inteligência, no drama em questão, é desvinculada do contexto do racionalismo simples, que Pessoa condena: "P'ra quê pensar, se há-de parar aqui/ O curto vôo do entendimento?/ Mais além! Pensamento, mais além!” (PESSOA, 1991, p. 7). O pensamento em Fausto é desvinculado, dessa maneira, do entendimento, é um pensamento que visa o além. Pensar não implicaria compreender, é outro tipo de pensamento que é posto.

Fausto, formalmente como uma alegoria, problematizaria, então, sua própria leitura. Adentrar o universo fáustico pessoano é ser lançado em um mundo de sombras onde 
qualquer compreensão formada se revela, em um momento segundo, errônea. Apesar de o drama poético ser uma alegoria, tanto em seu conteúdo quanto em sua forma, isto não sugere, como ocorre com as obras de vanguarda, que seu material seja manipulado como algo morto. Pelo contrário, Fausto, como alegoria, significa um mergulho na natureza do material utilizado: a Inteligência. Mergulho no sentido daquilo que Pessoa, em sua carta a Marinetti, concebeu como compreender, sentir, conhecer a forma como as coisas são produzidas, “a razão íntima (interna) das coisas" (PESSOA, 1998, p. 305). Portanto, se Fausto se põe, em sua forma, como uma alegoria isso se deve à atenção de Pessoa ao funcionamento da Inteligência ou ao funcionamento da mente.

Pode-se também buscar uma compreensão acerca da afirmação de Manuel Gusmão de que Fausto não ficara inacabado devido à falta de talento de Fernando Pessoa, mas porque seria, de fato, um poema inacabável:

Dito de outro modo, trata-se não só de um poema inacabado mas de um poema inacabável, de um poema impossível. E deve ser claro que, impossível, não por falta de tempo de vida, nem por falta de "talento" (ou do que por isso se possa entender). (GUSMÃO, 1986, p. 213)

Fernando Pessoa, em seu projeto para Fausto, evidencia o fato de o cerne temático do drama poético em questão ser a luta entre Inteligência e Vida. O poeta português, dessa forma, transforma a relação entre ter um corpo e ter uma mente numa relação negativa, para a qual uma solução torna-se impossibilitada. Assim sendo, compreende-se a impossibilidade inerente ao drama poético de Fernando Pessoa. Impossibilidade que diz respeito à atenção ao material proposto pelo seu projeto para a composição de Fausto: A Inteligência (simbolizada no drama pela figura de Fausto) haja vista que as tentativas por parte da Inteligência são sempre malfadadas. Ou melhor, Fausto empreende uma jornada inacabável ao perceber que se encontra no campo de uma não-imediatez (tudo "aponta para a outra coisa"). Entende, pois, que qualquer compreensão possível é sempre transitória. Acumulam-se, dessa forma, sistemas falhados, compreensões fugidias que nada esclarecem, mas que se tornam apenas mais material para a Inteligência analisar constantemente. Portanto, se a Inteligência não é capaz de uma compreensão unívoca das coisas, o trabalho do pensamento é inacabável, assim como o é o poema. 


\section{BIBLIOGRAFIA}

BENJAMIN, Walter. The origin of German tragic drama. London: Verso, 2003.

BÜRGER, Peter. Teoria da Vanguarda. São Paulo: Cosac Naify, 2008.

GADAMER, Hans-Georg. Verdade e Método. $3^{a}$ ed., Rio de Janeiro: Vozes, 1999.

GUSMÃO, Manuel. O poema impossivel: O Fausto de Pessoa. Lisboa: Editorial Caminho, 1986.

MAN, Paul de. Alegorias da Leitura: linguagem figurativa em Rousseau, Nietzsche, Rilke e Proust. Rio de Janeiro: Imago, 1996. Blindness and Insight. $2^{\mathrm{a}}$ ed. Minneapolis: University of Minnesota Press, 1988.

PESSOA, Fernando. Primeiro Fausto. São Paulo: Iluminuras, 1996. Fausto: tragédia subjectiva (fragmentos). Rio de Janeiro: Nova Fronteira, 1991. . Obras em Prosa. Rio de Janeiro: Nova Aguilar, 1998.

SOUZA, Josiane Maria de. O Fausto de Fernando Pessoa: a totalidade inatingível. Estudos Portugueses e Africanos. Campinas, nº 14, p 57- 69, Jul/ Dez. 1989.

Artigo recebido em 15 de Junho de 2012.

Artigo aprovado em 17 de Outubro de 2012. 